\title{
Relative poverty in female disability grant recipients in South Africa
}

\author{
Yvette Basson \\ LL.B LL.M (cum laude) LL.D (UWC) \\ Senior lecturer, Department of Mercantile and Labour Law, UWC
}

\begin{abstract}
SUMMARY
It is a well-established fact that adequate social security measures are used as a tool to allow persons a measure of financial security and support in the event of certain contingencies. Historically, disability has been one of the "core" contingencies, which is covered by social security schemes. The purpose of social security in providing for this contingency is to compensate for income lost or reduced as a result of disability. The fact that more women in South Africa have disabilities than men leads to the conclusion that women with disabilities are more negatively affected by poverty than men with disabilities. This in turn makes a woman with a disability more likely to be dependent on the disability grant than a man with a disability. The link between gender, disability and poverty will be discussed to illustrate the socio-economic position of female disability grant recipients in comparison to male disability grant recipients. This article will address the relative poverty of female disability grant recipients and make recommendations to address this relative poverty.
\end{abstract}

\section{Introduction}

It is a well-established fact that adequate social security measures are used as a tool to allow persons a measure of financial security and support in the event of certain contingencies. ${ }^{1}$ Historically, disability has been one of the "core" contingencies, which is covered by social security schemes. The purpose of social security in providing for this contingency is to compensate for income lost or reduced as a result of disability. ${ }^{2}$ In many cases, social security is the only source of income for a woman with a disability who is unable to work (either because of her disability or because there are no viable employment opportunities available). ${ }^{3}$

In terms of section 27 of the Constitution, "[e]veryone has the right to have access to ... social security, including, if they are unable to support themselves and their dependants, appropriate social assistance". ${ }^{4}$ In the case of Khosa and Others $v$ Minister of Social Development and Others, ${ }^{5}$ the

1 Berghman Basic Concepts of Social Security (1991) 9; Dreze \& Sen Social security in developing countries (1991) 15.

2 ILO Social Security (Minimum Standards) Convention 102 of 1952.

3 Olivier (ed) et al Social Security: A legal analysis 313.

4 S 27(1)(c) of the Constitution of the Republic of South Africa, 1996.

5 Khosa $v$ Minister of Social Development, Mahlaule and another $v$ Minister of Social Development 20046 SA 505 (CC).

How to cite: Basson 'Relative poverty in female disability grant recipients in South Africa' 2021 
Constitutional Court considered the meaning of the word "everyone" for purposes of the right of access to social security. The word "everyone" was considered in light of the founding values of the Constitution, specifically equality. ${ }^{6}$ The Court found that the restriction of the word "everyone" to citizens did not comply with the guarantee of constitutional rights to "all people in our country" as per section 7(1) of the Bill of Rights. It therefore stands to reason that this "everyone" in section 27(1)(c) includes women with disabilities. Read with this in mind, section 27(1)(c) provides that women with disabilities have the right of access to social security, including social assistance.

Social security in South Africa is made up of two primary branches, which are social assistance and social insurance. ${ }^{7}$ Social assistance consists of a number of social grants administered by the state paid to qualifying individuals. The payment of a social grant is linked to the meeting of certain criteria by an applicant for a particular grant. ${ }^{8}$ The categories of persons eligible to apply for social grants in South Africa are older persons, children, war veterans and persons with disabilities. ${ }^{9}$ Social assistance measures are funded solely by the state, using funds generated by general revenue. ${ }^{10}$ Social insurance in South Africa is inextricably linked to employment, and social insurance measures include unemployment insurance, compensation for occupational injuries and diseases and retirement funds. ${ }^{11}$ Social insurance benefits are funded largely by contributions made by or on behalf of individuals who are formally employed. ${ }^{12}$ Examples include occupational retirement funds and the Compensation for Occupational Injuries and Diseases Fund. The focus of this article is social assistance, in the form of the disability grant.

The rates of disability amongst persons in South Africa differ substantially between men and women. In 2018, 6.4 per cent of men had a disability compared with 8.9 per cent of women. ${ }^{13}$ While these numbers alone do not seem to indicate a large disparity between the levels of poverty experienced by women and men with disabilities in South Africa, the link between disability and poverty must be borne in mind. Poverty and disability are cyclical, in that poverty has been

$6 \quad$ Khosa $v$ Minister of Social Development supra, 42.

7 Malherbe \& Wakefield "The effect of women's care-giving role on their social security rights" 2009 Law, Democracy and Development 47.

$8 \quad$ Khosa $v$ Minister of Social Development supra, 47.

9 Social Assistance Act 13 of 2004.

10 Strydom et al Essential Social Security (2006) 7.

11 Wiid The right to social security of persons with disabilities in South Africa (LLD thesis 2015 UWC) 13.

12 Olivier \& Mpedi "The extension of social protection to non-formal sector workers - experiences from SADC and the Caribbean" (2005) 19 Zeitschrift fur auslandisches und internationals Arbetis- und Sozialrecht (ZIAS) 152.

13 Statistics South Africa "Marginalised Groups Indicator Report 2018" (2019) 94. 
identified as a cause of disability as well as a factor that exacerbates the effects of disability. ${ }^{14}$ The fact that more women in South Africa have disabilities than men leads to the conclusion that women with disabilities are more negatively affected by poverty than men with disabilities. This in turn makes a woman with a disability more likely to be dependent on the disability grant than a man with a disability.

In the first section of this article, the link between gender, disability and poverty will be discussed to illustrate the socio-economic position of female disability grant recipients relative to male disability grant recipients. The latter part of the article will discuss certain aspects of the disability grant that may be considered problematic for female disability grant recipients. Before this discussion commences, a brief description of the purpose and eligibility criteria of the disability grant will be provided.

\section{The eligibility criteria of the disability grant}

The purpose of social assistance is to provide financial benefits to persons who are unable to provide for their own maintenance needs. ${ }^{15}$ The Social Assistance Act of 2004 (the SAA) ${ }^{16}$ is the definitive legislation governing social assistance in South Africa. The SAA identifies the persons who are entitled to apply for various social grants, and the types of grants themselves are listed along with the respective eligibility criteria. Section 9 of the SAA establishes the criteria for the disability grant and reads as follows: "[a] person is, subject to section 5, eligible for a disability grant, if he or she (a) has attained the prescribed age; and (b) is owing to a physical or mental disability, unfit to obtain by virtue of any service, employment or profession the means needed to enable him or her to provide for his or her maintenance".

The complete list of requirements which must be met in order for an application for the disability grant to be successful can thus be found in sections 5 and 9 of the Social Assistance Act, and these requirements are explained in, and supplemented by, the "Regulations relating to the application for and payment of social assistance and the requirements of conditions in respect of eligibility for social assistance" (the Regulations). ${ }^{17}$ The eligibility criteria for the grant may be summarised as follows: the applicant must be at least 18 years of age; the applicant must not be able to provide for his own maintenance as a result of a physical or mental disability; the applicant must be resident in South Africa at the time of making the application; the applicant must be a

14 Department of Social Development "Draft White Paper on a National Disability Rights Policy” (2014) 6.

15 S 27(1)(d) of the Constitution.

16 Social Assistance Act 13 of 2004.

17 Regulations to the Social Assistance Act 13 of 2004 relating to the application for, and payment of, social assistance and the requirements or conditions in respect of eligibility for social assistance (Reg 898 in GG 31356). 
South African citizen or permanent resident; and the applicant must meet the requirements of a means test. ${ }^{18}$ In addition, the applicant may not be cared for in a state institution, ${ }^{19}$ nor may they receive another social grant for themselves. ${ }^{20}$ The disability grant is non-contributory, which means that recipients of the grant need not have made any contributions in order to qualify for the grant, ${ }^{21}$ although there is an element of financial need that must be proved. A successful applicant for the disability grant must prove that they do not have income or assets that exceed certain pre-determined thresholds. ${ }^{22}$ If an applicant does not meet this requirement, they have failed to comply with the means test, which means they do not qualify for the disability grant.

\section{Poverty, disability and gender in South Africa}

Poverty is a complex concept, which encompasses a number of factors and variables. ${ }^{23}$ For this reason, it is important to clarify the meaning of the word "poverty" as it will be used throughout this article. Generally, poverty is a measure of resources available to meet needs experienced. 24 The concept of "absolute poverty" provides that a person experiences poverty if they are unable to meet a certain pre-determined standard of consumption. In other words, should a person have less resources available than the pre-determined acceptable standard, that person is considered to experience poverty. The approach of absolute poverty is thus linked to the development and use of a "poverty line" or threshold, below which all persons are deemed to experience poverty. ${ }^{25}$ One of the major disadvantages of the absolute poverty approach is that it only takes into account the position of a person or family in relation to the established poverty line, regardless of the specific resources available to that person or family. 26 This approach also does not consider the position of persons or families in relation to each other, in a realistic comparison. Absolute poverty is not concerned with an adequate standard of living, but rather focuses on financial need exclusively. ${ }^{27}$ The social and cultural needs of persons and families are not taken into consideration when measuring absolute poverty. Absolute poverty is preferred when studying developed countries whereas the relative

18 S 5(2)(b) of the SAA.

19 Regulation 3 read with regulation $2(\mathrm{~d})$.

20 Regulation 3 read with regulation 2(e)

21 S 5(2)(b) of the SAA.

22 For the current income and asset thresholds, see SASSA "You and your grant" https://www.sassa.gov.za/publications/Documents/You \% 20and \% 20 Your \% 20Grants \% 202020\% 20-\%20English.pdf.

23 Foster "Absolute versus relative poverty" 1998 88(2) American Economic Review 335.

24 Foster (1998) American Economic Review 335.

25 Hagenaars \& Van Praag "A synthesis of poverty line definitions" 1985 31(2) Review of Income and Wealth 139.

26 OECD Development Centre "On the relevance of relative poverty for developing countries" 2012 Working Paper No 3145.

27 OECD Development Centre 2012 Working Paper No 3145. 
poverty approach is preferred when studying developing countries. ${ }^{28}$ The relative poverty approach provides that persons experience poverty if their standard of living is below that of others in the same societal context. $^{29}$ While this approach takes into consideration the economic status of persons similarly to the absolute approach, the relative approach also takes into consideration other factors which contribute to a specific standard of living of persons. ${ }^{30}$ It is the relative approach which is preferable and is used throughout this article, since this approach provides information on whether a person experiences greater or less poverty than others in a similar situation.

Poverty and disability are inextricably linked, in that poverty contributes to the likelihood of occurrence of disability, and disability increases the likelihood of poverty. ${ }^{31}$ To address the challenges faced by female disability grant recipients in South Africa, the overall socioeconomic position of women with disabilities in South Africa must be carefully considered.

\section{Education, employment, and gender}

When the reported statistics on the education of women with disabilities are examined, a rather bleak picture is drawn. Women with disabilities are under-represented at all levels of education. ${ }^{32}$ Women with disabilities in South Africa are less likely to have completed grade 12 than men with disabilities. The percentage of women with disabilities that have little or no schooling is approximately 80 per cent. ${ }^{33}$ In and of itself, this is a shocking figure. In real terms this equates to approximately 1,57 million women with disabilities who have not completed grade $12 .{ }^{34}$ In comparison, approximately 74 per cent of men with disabilities have not completed grade $12 .^{35}$ While this percentage seems only slighter lower than for women with disabilities, the actual number is approximately 930000 . This means that there are approximately 640000 more women with disabilities who have not completed grade 12 than men with disabilities. This is clearly indicative of ongoing marginalisation of women with disabilities in relation to their male peers with disabilities.

The figures are similarly dismal when one compares the percentage of women without disabilities who have not completed grade 12 to the

28 OECD Development Centre 2012 Working Paper No 3145.

29 Chen \& Ravallion "More relatively poor people in a less absolutely poor world" 2013 59(1) Policy Research Working Paper 1.

30 Speder \& Kapitany "Poverty and deprivation: assessing demographic and social structural factors" 2005 Demographic Research Institute, Budapest Working Papers On Population, Family and Welfare No 8.

31 Department of Social Development (2014) 6.

32 Statistics South Africa (2019) 95.

33 Statistics South Africa (2019) 95.

34 This figure was arrived at by applying the percentage of women with disabilities who have little or no schooling to the total number of women with disabilities in South Africa.

35 Statistics South Africa (2019) 95. 
percentage of women with disabilities as established above. The number of women without disabilities who have not completed grade 12 is approximately 7,3 million. ${ }^{36}$ This amounts to 52 per cent of the population of women without disabilities. ${ }^{37}$ This is substantially less than the 80 per cent of women with disabilities who have not completed grade $12 .{ }^{38}$ The proportion of women with disabilities who have not completed grade 12 is thus substantially higher than the proportion of women without disabilities. The fact that so many women with disabilities have not completed grade 12 is a substantial barrier to participation in the workforce. This in turn has a negative impact on the earning capacity of women with disabilities which reinforces the cyclical nature of poverty and disability discussed above, and results in a greater likelihood of dependence on the disability grant. The Commission on Employment Equity (CEE) has found that the percentage of persons with disabilities at all levels of employment from unskilled to top management hovers around the 1 per cent mark. ${ }^{39}$ As the level of skill required decreases, the number of women with disabilities employed increases. ${ }^{40}$ This shows that women with disabilities are more often employed in jobs requiring less skill, with a concomitant decrease in salary or wages. There is no level of employment at which more women with disabilities are employed than men with disabilities. This is indicative of the continued marginalisation of women with disabilities in the workforce, since women with disabilities are poorly represented at all levels of employment, which hinders their access to income. Once again, this reinforces the relationship between disability and poverty and leads to women with disabilities being more likely to experience relative poverty and being reliant on the disability grant as their primary source of income.

\section{Costs associated with being female}

One of the problems with the disability grant lies in the fact that the amount payable to both male and female recipients of the grant is extremely low. As of 1 April 2021, a disability grant recipient gets R1890 per month. ${ }^{41}$ Considering that the national minimum wage equates to approximately R3750 per month, ${ }^{42}$ it is evident that the amount payable in terms of the disability grant is not sufficient to meet the maintenance needs of a recipient. One must, however, take into consideration the

36 Statistics South Africa (2019) 95.

37 This figure was arrived at by calculating the number of women with disabilities who have not completed grade 12 as a percentage of the total number of women with disabilities in South Africa.

38 Statistics South Africa (2019) 93.

39 Commission for Employment Equity “Annual Report 2018 - 2019” (2019).

40 Statistics South Africa (2019) 93 - 95.

41 Budget Speech 2021 available at http://www.treasury.gov.za/documents/ national\%20budget/2021/speech/speech.pdf (accessed on 2021-03-09). The amount of R1890 is the ordinary amount payable in terms of the disability grant, notwithstanding any temporary increases in the amount as a result of COVID-19 relief measures. 
internal limitations on the right of access to social security, namely that the state must "take reasonable legislative and other measures, within its available resources, to achieve the progressive realisation" of the right. ${ }^{43}$ These internal limitations will be addressed below.

As mentioned above, there are more women with a disability in South Africa than men. This means that there is a greater likelihood that a woman with a disability experiences poverty, in light of the cyclical link between disability and poverty. Women with disabilities face additional expenses related to their disability ${ }^{44}$ and additional expenses associated with being female. ${ }^{45}$ While male disability grant recipients are also faced with additional expenses relating to their disability, male disability grant recipients are not also forced to pay the "pink tax", that is, the costs associated with being a woman. ${ }^{46}$ Examples of items that form part of the pink tax are sanitary towels and tampons, birth control measures and expenses related to pregnancy and birth. Sanitary products are not provided free of charge in South Africa. This aspect of the pink tax has been highlighted internationally, and there are many campaigns that address this issue. ${ }^{47}$ Until sanitary products are provided free of charge, female disability grant recipients are expected to pay for these items from the meagre amount they receive through social assistance each month.

Costs associated with pregnancy, lactation and birth are often also be covered from the monthly amount paid to disability grant recipients. It should be noted that South Africa does have a free basic healthcare system that covers some aspects of pregnancy and birth. The existing free public healthcare system in South Africa is available to women with disabilities who cannot afford private treatment. ${ }^{48}$ These services are currently listed as applying to pregnant and lactating women and include the termination of pregnancy. ${ }^{49}$ The existing free public healthcare

42 This is based on the minimum hourly wage of R21,69 and a working week of 40 hours. See s 6(6) read with Schedule 1 of the National Minimum Wage Act 9 of 2018.

43 S 27(2) of the Constitution.

44 Independent Lives "Disability Related Expenses Explained" available at https://www.independentlives.org/disability-related-expenses-explained (accessed on 2020-09-30).

45 Bennett "The Tampon Tax: Sales Tax, Menstrual Hygiene Products, and Necessity Exemptions" 2017 The Business Entrepreneurship and Tax Law Review 183; Lafferty "The pink tax: the persistence of gender price disparity" 2019 Midwest Journal of Undergraduate Research 57.

46 Bennett (2017) 183.

47 Barbier "South Africa commits to providing free sanitary pads to girls" https://www.globalcitizen.org/en/content/south-africa-2019-budget-mhm (accessed on 2021-03-29).

48 S 4(1) of the National Health Act 61 of 2003.

49 S 4(3) of the National Health Act 61 of 2005. 
system is not without its challenges and shortcomings. ${ }^{50}$ Overcrowded facilities, staff shortages and inaccessible clinics and hospitals are just some of the barriers women with disabilities face when trying to access basic healthcare in South Africa. This effectively means that health related expenses may also have to be paid from the monthly disability grant amount.

Since women with disabilities have some form of medical condition that they will need treatment for, it is submitted that such treatment should be heavily subsidised or completely free. The existing free public healthcare system in South Africa is available to women with disabilities who cannot afford private treatment. ${ }^{51}$ These services are currently listed as applying to pregnant and lactating women and include the termination of pregnancy. ${ }^{52}$ It is submitted that the range of services should be expanded in order to provide better health and rehabilitation services for women with disabilities. Such expansion is permitted in terms of the National Health Act, which provides that the Minister of Health must ensure the provision of essential health services. ${ }^{53}$

The state has in fact endeavoured to introduce free universal healthcare through the introduction of the National Health Insurance (NHI). ${ }^{54}$ The premise of the NHI is that the general standard and quality of services as well as the range of services will be improved in comparison to the existing public healthcare system. ${ }^{55}$ The NHI provides the ideal opportunity for the continued marginalisation of women with disabilities in the area of medical treatment to be addressed and hopefully eliminated altogether. It must of course be borne in mind that the right of access to healthcare must be realised progressively, ${ }^{56}$ and the introduction of the NHI will not eradicate all such marginalisation immediately. The value of the NHI must not be overlooked when considering how to alleviate the burden of costs associated with by providing adequate and free health care. It is thus submitted that the health care of women with disabilities must be prioritised in the current and future public healthcare system in South Africa and women with disabilities should be specifically included in forward planning in the sphere of healthcare.

50 See Maphumulo \& Bhengu "Challenges of quality improvement in the healthcare of South Africa post-apartheid: A critical review" 2019 Curationis for a thorough discussion of the practical problems in the current public healthcare system in South Africa.

51 S 4(1) of the National Health Act 61 of 2003

52 S 4(3) of the National Health Act 61 of 2005.

53 S 3(1)(d) of the National Health Act 61 of 2005.

54 Department of Health "National Health Insurance" available at http:// www.health.gov.za/index.php/nhi (accessed on 2020-10-01).

55 Department of Health "National Health Insurance" available at http:// www.health.gov.za/index.php/nhi (accessed on 2020-10-01).

56 S 27(2) of the Constitution read with section 3 of the National Health Act 61 of 2005 . 


\section{Costs associated with caregiving}

In many African societies, including South Africa, women are more likely to be the primary caregivers in a household. ${ }^{57}$ This means that women are more likely to take responsibility for the wellbeing of the members of the household, including children, grandparents and extended family living in the same home. Being the primary caregiver often includes providing financially for other persons. Providing this care comes at a financial cost, in that it can prevent women from seeking employment outside the home. ${ }^{58}$ This in turn makes it more likely for a female caregiver to be unemployed ${ }^{59}$ and, in the case of a female caregiver with a disability, more likely to create dependence on the disability grant. It should be noted that there are additional grants available to persons who are the primary caregivers of children, namely the child support grant and the care dependency grant in the case of the child with a disability. ${ }^{60}$ Since these amounts are extremely low, they do little to offset the costs involved in being the primary caregiver of a child or children. ${ }^{61}$

There are also more households where the head of the household is a woman with a disability than there are households where the head of the household is a women without a disability. ${ }^{62}$ Similarly, women with disabilities were the head of 53.6 per cent of households compared with 46.3 per cent of men with a disability. ${ }^{63}$ While statistics do not show how many of these female headed households are reliant on the disability grant, the principle of relative poverty is illustrated through these numbers. The number of households headed by women with disabilities affects the levels of poverty experienced by these women with disabilities, since they bear the brunt of providing for their households. In addition, female disability grant recipients are faced with increased expenses relating to both their sex and their disability in comparison to households headed by other persons. It is therefore submitted that a female disability grant recipient who is the head of her household is more likely to experience relative poverty than a male disability grant recipient who is the head of his household, as well as a female without a disability who is the head of her household.

57 Wright, Noble, Ntshongwana, Neves, Barnes "South Africa's child support grant and the dignity of female caregivers" (2014) 1.

58 Malherbe \& Wakefield 2009 Law, Democracy and Development 47.

59 Malherbe \& Wakefield 2009 Law, Democracy and Development 48.

60 Malherbe \& Wakefield 2009 Law, Democracy and Development 55.

61 As of April 2021, the amount payable in terms of the child support grant is R460 per child and the amount payable in terms of the care dependency grant is R1890.

62 Statistics South Africa 201994

63 Statistics South Africa 201994. 


\section{Internal limitations on the right of access to social security}

From the above discussion, it is clear that a female disability grant recipient is expected to cover more expenses with the same amount of money given to a male disability grant recipient. It is submitted that giving the same amount of money to a male disability grant recipient and a female disability grant recipient is effectively an application of formal equality, ${ }^{64}$ that is, the same treatment between groups of persons. Formal equality is essentially a theory of equality which does not take into consideration the fact that certain situations may demand that persons be treated differently for them to have equality in practice and that treatment which is the same may have an indirect discriminatory impact. ${ }^{65}$ This identical treatment consequently leaves the female disability grant recipient at a comparative financial disadvantage. This in turn creates a situation where a female disability grant recipient is less able to meet their maintenance needs than a male disability grant recipient since the increased expenses relating to gender are not offset.

It is submitted that giving the same amount of money to male and female disability grant recipients amounts to indirect unfair discrimination. Sections 9(3) and (4) of the Constitution provide that neither the state nor any other person may unfairly discriminate on certain grounds directly or indirectly. A test for determining direct unfair discrimination was subsequently established by the Constitutional Court in Harksen $v$ Lane. ${ }^{66}$ The test presupposes that there is some form of differentiation taking place between groups, but this is not the case here. Male and female disability grant recipients receive precisely the same amount. However, any law or policy that has the effect of unfair discrimination, even if it appears to be neutral and non-discriminatory, will be considered as being indirectly unfairly discriminatory. ${ }^{67}$ This principle is well established in South African jurisprudence. In City Council of Pretoria $v$ Walker, it was held that:

"[t]he inclusion of both direct and indirect discrimination within the ambit of the prohibition imposed by section 8(2) evinces a concern for the consequences rather than the form of conduct. It recognises that conduct which may appear to be neutral and non-discriminatory may nonetheless result in discrimination, and if it does, that it falls within the purview of section $8(2) "$. 68

The increased expenses encountered by female disability grant recipients hinder their use of the funds received to meet their own maintenance needs which results in female disability grant recipients

64 Currie \& De Waal Bill of Rights Handbook (2013) 213.

65 Botha and Another $v$ Mthiyane and Another 20021 SA 289 (W) 67

66 Harksen $v$ Lane 19981 SA 300 (CC) para 53.

67 Currie \& De Waal (2013) 238.

68 City Council of Pretoria $v$ Walker 19982 SA 363 para 31. 
experiencing poverty relative to male disability grant recipients. It is therefore submitted that the payment of the same amount of money to male and female disability grant recipient amounts to indirect unfair discrimination on the basis of sex and / or gender, and the amount payable to female disability grant recipients should therefore be reconsidered in order to take into account the costs associated with being female. Such a review is not straightforward, however, since there are finite funds available to distribute through social assistance. This then raises the issue of the internal limitations on the right of access to social security in the Constitution.

Section 27(2) provides that the state must take "reasonable legislative and other measures" in order to fulfil the rights in section 27, which includes social security. According to the Constitutional Court, in evaluating measures taken by the state to ensure access to social security the court is not concerned with the availability of "more desirable" measures, but rather with whether the measures taken were "reasonable". 69 The court recognises that many different measures may be considered reasonable in any set of circumstances and, as long as the particular measures chosen can be considered reasonable in the circumstances, this requirement is met. ${ }^{70}$ There is thus no established test for reasonableness, and the reasonableness of a series of measures must be considered on a case by case basis. In determining whether a particular programme is reasonable, the programme must be considered in the context of the problem it aims to address, and the programme itself must be balanced and flexible. ${ }^{71}$ The Court also emphasises the importance of realising rights for persons whose needs are most urgent, and whose ability to enjoy rights is most in peril. ${ }^{72}$ It is submitted that female disability grant recipients are extremely unlikely to enjoy the full realisation of their rights, considering the urgent financial need that female disability grant recipients in South Africa experience.

According to the Constitutional Court in the Grootboom case,

"the goal of the Constitution is that the basic needs of all in our society be effectively met and the requirement of progressive realisation means that the state must take steps to achieve this goal. It means that accessibility should be progressively facilitated: legal, administrative, operational and financial hurdles should be examined and, where possible, lowered over time."73

In the context of the disability grant, progressive realisation requires only that the grant be accessible and not unduly exclusive. This is the case with the disability grant at this stage, since any woman with a disability may apply for the grant, provided she meets the requirements as set out in the SAA.

69 Government of the Republic of South Africa $v$ Grootboom and others 20011 SA 46 (CC) para 41.

70 Government of the Republic of South Africa $v$ Grootboom para 41.

71 Government of the Republic of South Africa $v$ Grootboom para 43.

72 Government of the Republic of South Africa $v$ Grootboom para 44.

73 Government of the Republic of South Africa $v$ Grootboom para 45. 
The most important of the internal limitations for purposes of the present discussion is the issue of available resources. The problem of funding social security measures is ever-present, and this has been taken into consideration by the drafters of the Constitution. ${ }^{74}$ Essentially, the right of access to social security is limited by the stipulation that the state is only compelled to provide social security benefits where it has the resources to do so. This means that the state may be able to avoid the issue of the level of benefits paid to female disability grant recipients by proving that there are no funds to facilitate an increase in this amount. ${ }^{75}$ Social grants are funded through general revenue, which consists primarily of income tax contributions 96 and it has been recognised that the amount available for such expenditure is limited as a result of both the number of social grant recipients as well as the high unemployment rate in South Africa. ${ }^{77}$ As of the fourth quarter in 2020, there were approximately 15 million persons who were employed, ${ }^{78}$ whereas the number of social grants paid was approximately 18,3 million. ${ }^{79}$ This does not mean, however, that the state should not review the amount payable to disability grant recipients from time to time. Even though this may be an onerous task, it is submitted that such a review is necessary to compensate for the increased expenses experienced by female disability grant recipients which leads to indirect discrimination being experienced by these recipients.

\section{Conclusion and recommendations}

As established above, female disability grant recipients are experiencing relative poverty to their peers. This is because of the combination of increased costs associated with being female and increased costs associated with having a disability. The disability grant does not currently take into consideration these increased costs and female disability grant recipients are therefore expected to cover more expenses with the same amount of money as male disability grant recipients. This effectively results in indirect unfair discrimination on the basis of sex.

The primary recommendation in this article is that the state should undertake a review of the amount payable to female disability grant recipients and attempt to address the current situation of indirect unfair discrimination by increasing this amount. While the issue of available resources remains relevant, indirect discrimination resulting in relative

\footnotetext{
74 Government of the Republic of South Africa $v$ Grootboom para 94.

75 Olivier Introduction to Social Security (2004) 147.

76 National Treasury (2007) "Social Security and Retirement Fund Reform: Second discussion Paper" 11.

77 Khosa supra, para 45; Wiid (2015) 196.

78 Statistics South Africa "Quarterly Labour Force Survey 2020 Q4" http:// www.statssa.gov.za/publications/P0211/Presentation \% 20QLFS \% 20Q4_ 2020.pdf (accessed on 2021-03-09).

79 SASSA "Social grants payment report December 2020" https://www.sassa. gov.za/statistical-reports/Documents/Social \% 20Grant \% 20Payments \% 20 Report \% 20-\% 20December \% 202020.pdf (accessed on 2021-03-09).
} 
poverty being experienced is inconsistent with the values of equality and dignity which underpin the Constitution. The amount paid to female disability grant recipients must therefore be reconsidered.

Another way in which the relative poverty of female disability grant recipients as a group can be addressed is to make feminine hygiene and contraceptive products available for free. It would be incumbent on the state to make these products available free of charge since the state is obligated to realise the right of access to healthcare and is currently creating access to free healthcare through the existing public healthcare system. There is thus existing infrastructure in place that could facilitate the delivery of free feminine hygiene products to women with disabilities. The proposed NHI system could include the provision of these products in its range of services, should the system come into practice.

Since equality is one of the values that underpin the Constitution, the indirect discrimination experienced by female disability grant recipients must take priority in forward planning and any policies or programmes aimed at social development. The abovementioned recommendations are important tools that can be used to lessen the financial burden of being female and disabled in South Africa. Until such time as this unfair discrimination is addressed, female disability grant recipients will remain in a situation of relative poverty to their peers, despite playing an important role as family caregivers and valued members of society. 